\title{
Anatomy and morphometry of the distal gracilis muscle tendon in adults and foetuses
}

\author{
D.W. Dziedzic, U. Bogacka, I. Komarnițki, B. Ciszek \\ Department of Descriptive and Clinical Anatomy, Centre of Biostructure Research, Medical University of Warsaw, \\ Poland
}

[Received: 18 January 2017; Accepted: 27 April 2017]

\begin{abstract}
Ten human gracilis muscles obtained from adults and ten gracilis muscles collected from human foetuses between the $15^{\text {th }}$ and $21^{\text {st }}$ week of gestation were examined. The results of this preparatory study show that the gracilis muscle in adults is narrow and long - $482 \mathrm{~mm}$ on average. The distal tendon of gracilis muscle is long, $294 \mathrm{~mm}$ on average. It can be divided into two sections - external part, outside the muscle belly, and internal, intramuscular, part. The latter one is partially covered by muscle fibres and some of it is completely hidden inside the muscle belly, which is on average $76 \mathrm{~mm}$ long. Presence of an intramuscular part of the distal tendon was also demonstrated in the foetal material. Moreover, very strong correlations between particular muscle lengths were noted in foetuses. (Folia Morphol 2018; 77, 1: 138-143)
\end{abstract}

Key words: gracilis, pes anserinus, foetal muscle, tendon

\section{INTRODUCTION}

The gracilis muscle is located on the medial side of the thigh. In humans, it is long, often longer than $40 \mathrm{~cm}$, narrow, and weighs about $100 \mathrm{~g}[22,28,33]$. Fibres of such long muscles do not always run throughout the entire length of the muscle belly. It is believed that $30-50 \%$ of fibres at the most run from one tendon to another, while the remaining fibres terminate intrafascicularly $[13,15]$.

Gracilis belongs to a group of adductor muscles. It is the only one of them to extend between both joints - the hip and the knee. Its proximal attachment is located on medial margin of inferior public ramus and the ramus of the ischium. It begins with a broad, thin tendon. Its long, flat muscle belly runs down along the thigh. It subsequently passes around the medial epicondyle of the tibia and inserts into the superior medial surface of the tibia, medially to the tibial tuberosity $[20,26]$.
Several accessory bundles, usually 3-5, may emerge from the tendon at the distal end. They may run toward adjacent muscles or fascia [7, 39].

Distal insertion is a part of a structure known as pes anserinus. It is a plate formed by the distal parts of sartorius and semitendinosus muscle tendons, which are also attached to the crural fascia. For that reason pes anserinus ("goose foot") together with a group of muscles that form it are also sometimes known as tensor fasciae cruris $[18,24,27,41]$.

Gracilis muscle is innervated by the anterior branch of the obturator nerve [28].

There is a segmental arterial supply to the muscle by the external branches of femoral artery and branches of the deep artery of the thigh - mainly from the medial circumflex femoral artery. Vessels supplying this muscle make it a well pedunculated muscle flap $[11,19,20,21,28,33]$. 
Due to its characteristic placement, the muscle acts across two joints. In the hip joint it acts mainly as an adductor. Depending on the position of the hip joint it can extend or flex it, rotate it externally or internally. Together with other adductors it prevents excessive abduction. Acting on the knee joint, it flexes it and while in the flexed position, it rotates the tibia internally. Through its action on the knee joint it maintains body balance when placed on a broad, unstable object in between the lower limbs, for example during horse riding $[3,16,22,31]$.

Topography of the gracilis creates great possibilities for reconstructive and plastic surgery. Aside from being nourished on many levels, the gracilis flap is additionally characterised by extensive rotational range of the dissected fragment, enabling coverage of defects located within the perineum, sciatic as well as inguinal areas. Therefore, such flap can be applied in the reconstruction of the penis (also in the transsexuals), labia, or parts of the vagina as well as anal sphincters. It is possible to join an extensive island flap to the muscle flap. As the flap possesses a single vascular pedicle, it can be transferred to distant parts of the body as a free flap $[2,4,10,12$, $14,23,25,32,40]$.

Morphology of the distal tendon makes it a frequent choice as a graft in reconstruction of the anterior cruciate ligament and other knee joint ligaments, e.g. posterior cruciate ligament, collateral ligament, patellofemoral ligament [5, 29, 34, 35, 38]. The tendon of this muscle may also be used in more distant parts of the body, e.g. for reconstruction of the coracoclavicular ligament in dysfunction of the acromioclavicular joint [37].

A phenomenon was recently discovered relating to the fact that the distal tendon of the gracilis muscle rebuilds after harvesting [8]. The tendon grows back in most patients within the first year after tendotomy [6]. It grows in distal direction, reaching its attachment in the fascial and tendinous structures of the knee joint $[1,17]$.

The aim of the work was to evaluate the proportion of components of the gracilis muscle: the belly and the distal tendon, in adult as well as foetal specimen.

\section{MATERIALS AND METHODS}

Ten human gracilis muscles obtained from adults and ten gracilis muscles collected from human foetuses between 15 and 21 weeks of gestational age were examined. Examined muscles came from lower limb preparations and foetal preparations preserved in $10 \%$ formaldehyde solution that had been in possession of the local Department of Descriptive and Clinical Anatomy at the Medical University of Warsaw. Studies were carried out with classical methods of dissection. The foetal material required application of an surgical magnifying glass NY Dornwell 3.0X, Stereo microscope - Nikon SM 1500, and microsurgical tools. Morphometry of selected parts of muscles was examined and the photographic documentation was taken. Morphology and morphometry of the material from adults and foetuses were compared (Fig. 1).

During the study the following measurements were carried out in adult and foetal specimen labelled as follows:

- LLL - length of the lower limb measured from the anterior superior iliac spine to the medial malleolus;

- TL - length of the thigh measured from the anterior superior iliac spine to the medial aspect of knee joint gap;

- A - total length of the muscle, measured from origin to distal insertion;

- B - total length of the distal tendon;

- C - external part of the distal tendon - length of the part of the distal tendon outside the muscle belly; the section not covered by muscle fibres;

- D - internal part of the distal tendon - length of the tendon section partially and completely covered with muscle fibres;

- E - width of the muscle belly measured in the mid-part of muscle belly.

Additionally, the following measurements were obtained in adult specimen:

- F - length of the distal tendon section partially covered by the muscle belly;

- G - length of the distal tendon section completely hidden inside the muscle belly;

$-\mathrm{H}$ - length of the muscle belly.

Morphometric data results were subjected to basic statistical analysis, including calculation of the arithmetic means (avg.), standard deviations (SD) and ratios of $B / A, C / A, C / B, E / H$ as well as correlations between selected parameters.

\section{RESULTS}

Results of morphometric examinations of the gracilis muscle that were carried out on adult and on foetal specimen are presented in the Table 1. 

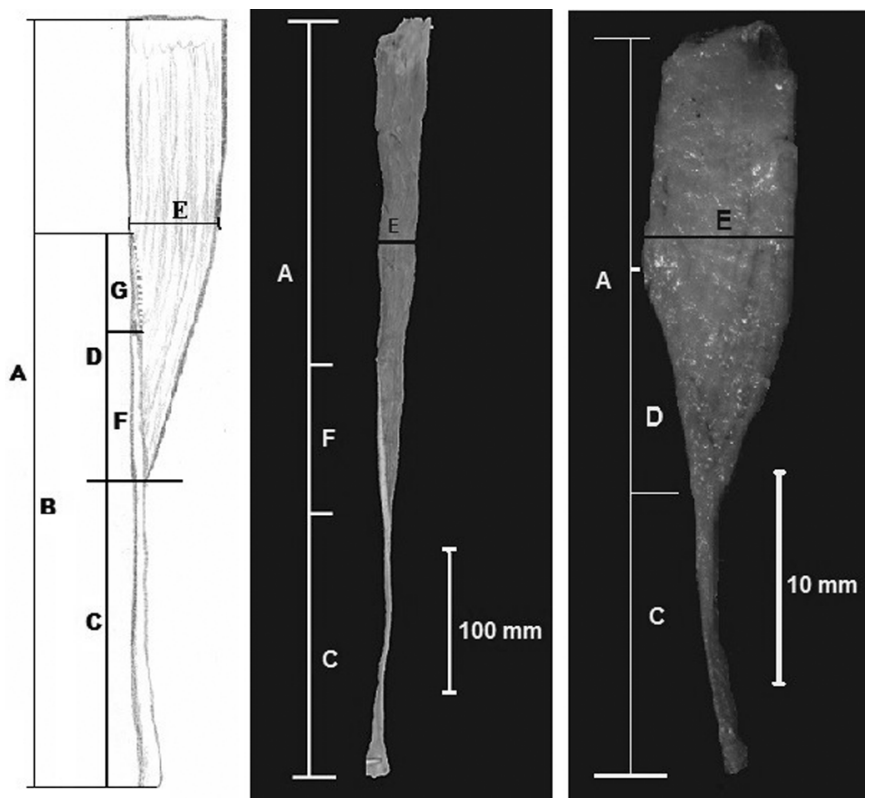

Figure 1. A scheme of gracilis muscle structure (left) in an adult (middle) and a foetus at 15 weeks of gestation (right). Selected morphological data were marked in the figures; $A, B, C, D, E, F, G$ - abbreviations see 'Materials and methods'.

Table 1. Morphological characteristics of the gracilis muscle in adults [mm]

\begin{tabular}{lccccccccccccccc}
\hline No. & LLL & TL & Side & A & B & C & D & E & F & G & H & E/H & B/A & C/A & C/B \\
\hline $\mathbf{1}$ & 750 & 440 & R & 420 & 230 & 100 & 130 & 35 & 65 & 65 & 320 & 0.11 & 0.55 & 0.24 & 0.43 \\
$\mathbf{2}$ & 790 & 460 & L & 470 & 250 & 120 & 130 & 25 & 75 & 55 & 350 & 0.07 & 0.53 & 0.26 & 0.48 \\
$\mathbf{3}$ & 840 & 500 & L & 490 & 310 & 140 & 170 & 34 & 40 & 130 & 350 & 0.097 & 0.63 & 0.29 & 0.45 \\
$\mathbf{4}$ & 890 & 520 & $\mathrm{~L}$ & 500 & 330 & 160 & 170 & 38 & 90 & 80 & 340 & 0.11 & 0.66 & 0.32 & 0.48 \\
$\mathbf{5}$ & 850 & 500 & $\mathrm{~L}$ & 530 & 290 & 150 & 140 & 36 & 50 & 90 & 380 & 0.09 & 0.55 & 0.28 & 0.52 \\
$\mathbf{6}$ & 920 & 540 & $\mathrm{~L}$ & 500 & 340 & 140 & 200 & 40 & 105 & 95 & 360 & 0.11 & 0.68 & 0.28 & 0.41 \\
$\mathbf{7}$ & 910 & 520 & $\mathrm{~L}$ & 530 & 320 & 160 & 160 & 28 & 100 & 60 & 370 & 0.08 & 0.60 & 0.3 & 0.5 \\
$\mathbf{8}$ & $\mathbf{7 7 0}$ & 450 & $\mathrm{~L}$ & 430 & 260 & 130 & 130 & 28 & 110 & 20 & 300 & 0.09 & 0.60 & 0.3 & 0.5 \\
$\mathbf{9}$ & 930 & 540 & $\mathrm{~L}$ & 490 & 330 & 140 & 190 & 30 & 90 & 100 & 350 & 0.09 & 0.67 & 0.29 & 0.42 \\
$\mathbf{1 0}$ & $\mathbf{7 8 0}$ & 430 & $\mathrm{~L}$ & 460 & 280 & 150 & 130 & 25 & 65 & 65 & 310 & 0.08 & 0.61 & 0.33 & 0.54 \\
Avg. & $\mathbf{8 4 3}$ & $\mathbf{4 9 0}$ & & $\mathbf{4 8 2}$ & $\mathbf{2 9 4}$ & $\mathbf{1 3 9}$ & $\mathbf{1 5 5}$ & $\mathbf{3 1 . 9}$ & $\mathbf{7 9}$ & $\mathbf{7 6}$ & $\mathbf{3 4 3}$ & $\mathbf{0 . 0 9}$ & $\mathbf{0 . 6 1}$ & $\mathbf{0 . 2 9}$ & $\mathbf{0 . 4 7}$ \\
$\mathbf{S D}$ & $\mathbf{6 7 . 5}$ & $\mathbf{4 1 . 6}$ & & $\mathbf{3 7 . 4}$ & $\mathbf{3 8 . 1}$ & $\mathbf{1 8 . 5}$ & $\mathbf{2 6 . 8}$ & $\mathbf{5 . 4}$ & $\mathbf{2 3 . 8}$ & $\mathbf{3 0 . 1}$ & $\mathbf{2 5 , 8}$ & $\mathbf{0 . 0 1}$ & $\mathbf{0 . 0 5}$ & $\mathbf{0 . 0 3}$ & $\mathbf{0 . 0 4}$ \\
\hline
\end{tabular}

Abbreviations - see text

Gracilis muscle runs between the inferior pubic ramus, the ramus of the ischium and the proximal end of tibia. In adults, the muscle belly is narrow (31.9 \pm $\pm 5.4)$ and long $(343 \pm 5.1)$. The distal tendon of the muscle is extremely long: $294 \pm 38.1 \mathrm{~mm}$. Its total length is measured from the origin of fibres hidden inside the muscle belly to the distal insertion of the tendon. The distal tendon contains an external part, visible on the outside, completely free from muscle fibres; its length being $294 \pm 38.1 \mathrm{~mm}$ on average.
Moreover, there is also an internal part of the distal tendon, either partially covered by muscle fibres or completely hidden inside the muscle belly. Length of the section partially covered by muscle fibres was $79 \pm 23.8 \mathrm{~mm}$ while the average length of the part contained in the muscle belly was $76 \pm 30.1 \mathrm{~mm}$ (Table 1).

In foetuses, the belly is wider than in adults. The ratio of width to length of the belly in foetuses is 0.19 . It is two times greater than that found in adults (0.09). 


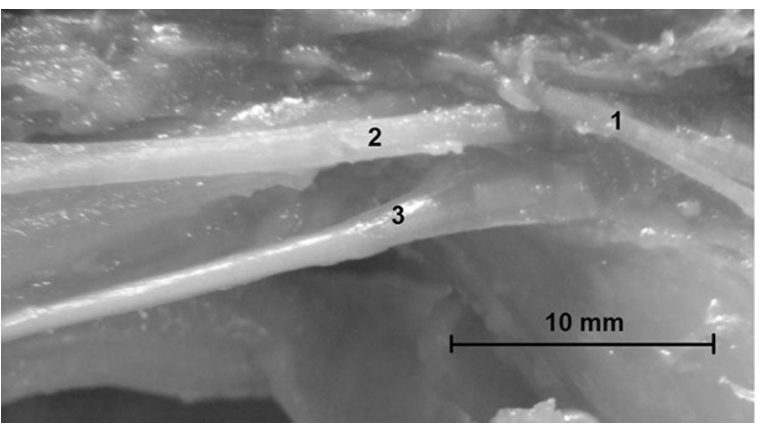

Figure 2. Pes anserinus in a foetus at 17 weeks of gestation. Distal tendons of the muscles: 1 - sartorius; 2 - gracilis; 3 - semitendinosus.

Examinations carried out on the foetal material confirmed the presence of both the internal and the external parts of the distal tendon.

Both in the adults as well as foetuses the distal tendon reaches its insertion medially to the tibial tuberosity, arranging itself between the distal tendons of sartorius and semitendinosus muscles, forming pes anserinus (Fig. 2).

In foetuses the distal tendon is relatively longer compared to adults (B/A). In foetuses, it constitutes (on average) 0.77 of the whole muscle length, while in adults the ratio is 0.61 . The differences in ratios of the length of external part of the tendon to the whole muscle $(C / A)$ were smaller; in foetuses average ratio was 0.34 , while in the adults it amounted to 0.29 .
The ratios of the length of the external part of the tendon to the total length of the tendon $(C / B)$ were similar in both groups: averaging 0.47 in adults and 0.44 in foetuses (Tables 1, 2).

In the adults the length of the muscle is highly correlated with the length of the lower limb (A-LLL), between the length of the muscle and the length of the thigh (A-TL), while the length of the whole tendon correlates with the length of the whole muscle (B-A) and the length of the external part of the tendon correlates with the length of the muscle (C-A).

Almost complete correlation is present between the length of the external part of the distal tendon and the length of the lower limb (B-LLL) as well as the length of the thigh.

In foetuses all of the above-mentioned correlations are almost complete (classification of correlations according to J. Guilford) (Table 3).

\section{DISCUSSION}

Gracilis is a long and narrow muscle ending with a cylindrical tendon. The length of the whole muscle determined in our material, $480 \mathrm{~mm}$ on average, did not differ significantly from morphometric data in the literature $[28,33]$. Larger discrepancies could be found in relation to the distal tendon. Available literature reports a broad range of dimensions, between $80 \mathrm{~mm}$ and $230 \mathrm{~mm}[30,33,36]$. This is due to the fact that only the visible part of the tendon

Table 2. Morphological characteristics of the gracilis muscle in the foetal material [mm]

\begin{tabular}{|c|c|c|c|c|c|c|c|c|c|c|c|c|c|c|}
\hline No. & HBD & LLL & $\mathrm{TL}$ & Side & A & B & C & D & $E$ & H & $\mathrm{E} / \mathrm{H}$ & $\mathrm{B} / \mathrm{A}$ & $\mathrm{C} / \mathrm{A}$ & C/B \\
\hline P1 & 17 & 87 & 52 & $L$ & 43 & 33 & 13 & 20 & 5.0 & 30 & 0.17 & 0.77 & 0.30 & 0.39 \\
\hline P2 & 21 & 124 & 72 & $\mathrm{~L}$ & 59 & 48 & 21 & 27 & 11 & 38 & 0.29 & 0.81 & 0.36 & 0.44 \\
\hline P3 & 21 & 126 & 73 & $\mathrm{R}$ & 60 & 50 & 22 & 28 & 10 & 38 & 0.26 & 0.83 & 0.37 & 0.44 \\
\hline P4 & 17 & 93 & 53 & $\mathrm{R}$ & 48 & 36 & 15 & 21 & 5.5 & 33 & 0.17 & 0.75 & 0.31 & 0.42 \\
\hline P5 & 17 & 92 & 53 & $\mathrm{~L}$ & 47 & 37 & 16 & 21 & 6.0 & 31 & 0.19 & 0.79 & 0.34 & 0.43 \\
\hline P6 & 17 & 88 & 49 & $\mathrm{~L}$ & 44 & 35 & 14 & 21 & 5.5 & 30 & 0.18 & 0.80 & 0.32 & 0.4 \\
\hline P7 & 15 & 82 & 50 & $\mathrm{R}$ & 41 & 32 & 15 & 17 & 4.0 & 26 & 0.15 & 0.78 & 0.37 & 0.47 \\
\hline P8 & 15 & 83 & 51 & $\mathrm{~L}$ & 41 & 31 & 14 & 17 & 4.0 & 27 & 0.15 & 0.76 & 0.34 & 0.45 \\
\hline P9 & 15 & 72 & 42 & $\mathrm{~L}$ & 37 & 26 & 13 & 13 & 5.0 & 24 & 0.17 & 0.70 & 0.35 & 0.5 \\
\hline P10 & 15 & 74 & 43 & $\mathrm{R}$ & 36 & 24 & 12 & 12 & 4.5 & 24 & 0.19 & 0.67 & 0.33 & 0.5 \\
\hline Avg. & 17 & 92.1 & 53.8 & & 45.6 & 35.2 & 15.5 & 19.7 & 6.05 & 30.1 & 0.19 & 0.77 & 0.34 & 0.44 \\
\hline SD & 2.31 & 18.64 & 10.57 & & 8.25 & 8.36 & 3.37 & 5.23 & 2.44 & 5.11 & 0.05 & 0.05 & 0.02 & 0.04 \\
\hline
\end{tabular}

Abbreviations - see text 
Table 3. Correlation coefficients for selected morphometric data

\begin{tabular}{lll}
\hline $\begin{array}{l}\text { Correlation } \\
\text { - morphometric symbol }\end{array}$ & Adult & Foetal \\
\hline A-LLL & & \\
A-TL & 0.795 & 0.992 \\
B-LLL & 0.764 & 0.975 \\
B-TL & 0.936 & 0.988 \\
B-A & 0.900 & 0.938 \\
C-A & 0.740 & 0.993 \\
D-A & 0.774 & 0.958 \\
C-B & 0.522 & 0.968 \\
D-B & 0.762 & 0.959 \\
\hline
\end{tabular}

Abbreviations - see text

or its fragment that had been successfully harvested without dividing into external and internal parts was measured. The total length of the tendon in our adult material ranged from $230 \mathrm{~mm}$ to $340 \mathrm{~mm}$. Length of the external part of the tendon outside muscle belly not covered by muscle fibres was significantly lesser, ranging 100-160 $\mathrm{mm}$.

The remaining fragment (the intramuscular part) is either partially or completely covered by muscle fibres. The length of the part totally contained inside muscle belly was 100-130 mm. Obviously, these dimensions were significantly smaller in foetuses although the proportions were similar. However, higher proportion of the total length of the tendon to the total length of the muscle is a reflection of smaller muscle mass in foetuses compared to adults.

We noted that both the external as well as internal parts of the distal tendon were present in the examined foetuses. Moreover, correlations between the lengths of the distal tendon and of the lower limb, thigh and the whole muscle were almost complete. Similarly, in the foetal material almost complete correlations were demonstrated between individual parts of the tendon and the total length of the distal tendon and muscle. In adults correlations between individual lengths were not as strong.

Long intramuscular course of the tendon enables attachment of a significantly greater number of muscle fibres in the distal area of the tendon. Intramuscular course of tendons is an insufficiently investigated and rarely described anatomical phenomenon [9] with potentially significant biomechanical and clinical implications.

\section{CONCLUSIONS}

These studies illustrate the complex anatomy of the gracilis muscle and the differences resulting from ontogenetic development. The main limitation of our work is a small number of specimens. A larger sample would be more representative and would allow for a more detailed statistical analysis. We plan to study other muscles, include a greater number of specimens, and perform imaging studies of the muscle-tendon unit in living individuals.

\section{REFERENCES}

1. Åhlén $M$, Lidén $M$, Bovaller $\AA$, et al. Bilateral magnetic resonance imaging and functional assessment of the semitendinosus and gracilis tendons a minimum of 6 years after ipsilateral harvest for anterior cruciate ligament reconstruction. Am J Sports Med. 2012; 40(8): 1735-1741, doi: 10.1177/0363546512449611, indexed in Pubmed: 22711582.

2. Aho T, Canal A, Neal D. Fournier's gangrene. Nat Clin Pract Urol. 2006; 3(1): 54-57, doi: 10.1038/ncpuro0353.

3. Arnold AS, Asakawa DJ, Delp SL. Do the hamstrings and adductors contribute to excessive internal rotation of the hip in persons with cerebral palsy? Gait Posture. 2000; 11(3): 181-190, indexed in Pubmed: 10802430.

4. Baeten CG, Geerdes BP, Adang EM, et al. Anal dynamic graciloplasty in the treatment of intractable fecal incontinence. N Engl J Med. 1995; 332(24): 1600-1605, doi: 10.1056/NEJM199506153322403, indexed in Pubmed: 7753138.

5. Borbas P, Koch PP, Fucentese SF. Lateral patellofemoral ligament reconstruction using a free gracilis autograft. Orthopedics. 2014; 37(7): e665-e668, doi: 10.3928/0147744720140626-66, indexed in Pubmed: 24992066.

6. Burks RT, Crim J, Fink BP, et al. The effects of semitendinosus and gracilis harvest in anterior cruciate ligament reconstruction. Arthroscopy. 2005; 21(10): 1177-1185, doi: 10.1016/j.arthro.2005.07.005, indexed in Pubmed: 16226644.

7. Candal-Couto JJ, Deehan DJ. The accessory bands of Gracilis and Semitendinosus: an anatomical study. Knee. 2003; 10(4): 325-328, indexed in Pubmed: 14629934.

8. Cross MJ, Roger G, Kujawa P, et al. Regeneration of the semitendinosus and gracilis tendons following their transection for repair of the anterior cruciate ligament. Am J Sports Med. 1992; 20(2): 221-223, doi: 10.1177/03635 4659202000223, indexed in Pubmed: 1558254.

9. Dziedzic D, Bogacka U, Ciszek B. Anatomy of the sartorius muscle. Folia Mophol. 2014; 73: 259-262.

10. Epstein DM, Arger PH, LaRossa D, et al. CT evaluation of gracilis myocutaneous vaginal reconstruction after pelvic exenteration. AJR Am J Roentgenol. 1987; 148(6): 1143-1146, doi: 10.2214/ajr.148.6.1143.

11. Hallock G. The Development of the Medial Circumflex Femoral Artery Perforator (MCFAP) Flap. Semin Plastic Surgery. 2006; 20(2): 121-126, doi: 10.1055/s-2006-941719. 
12. Hanash KA, Tur JJ. One-stage plastic reconstruction of a totally amputated cancerous penis using a unilateral myocutaneous gracilis flap. J Surg Oncol. 1986; 33(4): 250-253, indexed in Pubmed: 3784561.

13. Harris AJ. Muscle Fiber and Motor Unit Behavior in the Longest Human Skeletal Muscle. J Neurosci. 2005; 25(37): 8528-8533, doi: 10.1523/jneurosci.0923-05.2005.

14. Hassani E, Karimi H, Maghari A. Reconstructions of glans and distal urethra after traumatic circumcision. Case Rep Clin Pract Rev. 2005; 6: 292-295.

15. Heron MI, Richmond FJ. In-series fiber architecture in long human muscles. J Morphol. 1993; 216(1): 35-45, doi: 10.1002/jmor.1052160106, indexed in Pubmed: 8496969

16. Hoek van Dijke GA, Snijders CJ, Stoeckart R, et al. A biomechanical model on muscle forces in the transfer of spinal load to the pelvis and legs. J Biomech. 1999; 32(9): 927-933, indexed in Pubmed: 10460129.

17. Janssen RPA, van der Velden MJF, Pasmans HLM, et al. Regeneration of hamstring tendons after anterior cruciate ligament reconstruction. Knee Surg Sports Traumatol Arthrosc. 2013; 21(4): 898-905, doi: 10.1007/s00167012-2125-0, indexed in Pubmed: 22763570.

18. Je-Hun L, Kyung-Jin K, Young-Gil J, et al. Pes anserinus and anserine bursa: anatomical study. Anat Cell Biol. 2014; 47(2): 127-131.

19. Juricic $M$, Vaysse $P$, Guitard J, et al. Anatomic basis for use of a gracilis muscle flap. Surg Radiol Anat. 1993; 15(3): 163-168, indexed in Pubmed: 8235956.

20. Juricic $M$, Vaysse $P$, Visentin $M$, et al. [Gracilis muscle in man]. Bull Assoc Anat (Nancy). 1992; 76(232): 35-42, indexed in Pubmed: 1638060.

21. Kim CM, Yun InS, Lee DW, et al. Treatment of ischial pressure sores with both profunda femoris artery perforator flaps and muscle flaps. Arch Plast Surg. 2014; 41(4): 387-393, doi: 10.5999/aps.2014.41.4.387, indexed in Pubmed: 25075362.

22. Klein Horsman MD, Koopman H, van der Helm F, et al. Corrigendum to "Morphological muscle and joint parameters for musculoskeletal modelling of the lower extremity" [Clin. Biomech. 22 (2007) 239-247]. Clini Biomech. 2007; 23(10): 1303, doi: 10.1016/j.clinbiomech.2008.01.004.

23. Kua EeH, Leo KW, Ong YS, et al. Vascularisation of urethral repairs with the gracilis muscle flap. Arch Plast Surg. 2013; 40(5): 584-588, doi: 10.5999/aps.2013.40.5.584, indexed in Pubmed: 24086814.

24. LaPrade R, Ly T, Wentorf $F$, et al. The anatomy of the medial part of the knee. J Bone Joint Surg Am. 2007; 89(9): 2000-2010, doi: 10.2106/00004623-20070900000016.

25. Lee SH, Rah DK, Lee WJ. Penoscrotal reconstruction with gracilis muscle flap and internal pudendal artery perforator flap transposition. Urology. 2012; 79(6): 1390-1394, doi: 10.1016/j.urology.2012.01.073, indexed in Pubmed: 22656416

26. Meyers W, Greenleaf R, Saad A. Anatomic basis for evaluation of abdominal and groin pain in athletes. Oper Tech Sports Med. 2005; 13(1): 55-61, doi: 10.1053/j. otsm.2005.01.001.
27. Mochizuki T, Akita K, Muneta T, et al. Pes anserinus: layered supportive structure on the medial side of the knee. Clin Anat. 2004; 17(1): 50-54, doi: 10.1002/ca.10142, indexed in Pubmed: 14695588.

28. Morris SF, Yang D. Gracilis muscle: arterial and neural basis for subdivision. Ann Plast Surg. 1999; 42(6): 630-633, indexed in Pubmed: 10382799.

29. Norbakhsh ST, Zafarani Z, Najafi A, et al. Arthroscopic posterior cruciate ligament reconstruction by using hamstring tendon autograft and transosseous screw fixation: minimal 3 years follow-up. Arch Orthop Trauma Surg. 2014; 134(12): 1723-1730, doi: 10.1007/s00402-014-2082-9, indexed in Pubmed: 25186074.

30. Pichler W, Tesch NP, Schwantzer G, et al. Differences in length and cross-section of semitendinosus and gracilis tendons and their effect on anterior cruciate ligament reconstruction: A CADAVER STUDY. J Bone Joint Surg. 2008; 90-B(4): 516-519, doi: 10.1302/0301-620x.90b4.19994.

31. Pressel T, Lengsfeld $M$. Functions of hip joint muscles. Med Eng Phys. 1998; 20(1): 50-56, indexed in Pubmed: 9664285.

32. Ratliff CR, Gershenson DM, Morris M, et al. Sexual adjustment of patients undergoing gracilis myocutaneous flap vaginal reconstruction in conjunction with pelvic exenteration. Cancer. 1996; 78(10): 2229-2235, indexed in Pubmed: 8918419.

33. Singh H, Kaur R, Gupta N. Morphometric study of gracilis muscle and its role in clinical reconstruction. J Anat Soc India. 2011; 60(2): 202-206, doi: 10.1016/s00032778(11)80027-4.

34. Śmigielski R, Mioduszewski A. Rekonstrukcja więzadła pobocznego piszczelowego uszypułowanego dystalne ścięgnem mięśnia smukłego. Acta Clin. 2002; 2(2): 146-150.

35. Stolarczyk A, Nagraba $Ł$, Mitek T, et al. Porównanie dwóch metod artroskopowej rekonstrukcji więzadła krzyżowego przedniego, Artroskopia i Chirurgia Stawów. 2006; 2(3): 22-29.

36. Tohyama H, Beynnon BD, Johnson RJ, et al. Morphometry of the semitendinosus and gracilis tendons with application to anterior cruciate ligament reconstruction. Knee Surg Sports Traumatol Arthrosc. 1993; 1(3-4): 143-147, doi: 10.1007/bf01560195.

37. Virtanen KJ, Savolainen V, Tulikoura I, et al. Surgical treatment of chronic acromioclavicular joint dislocation with autogenous tendon grafts. Springerplus. 2014; 3(420): 1-8, doi: 10.1186/2193-1801-3-420, indexed in Pubmed: 25152850.

38. Wilson T, Lubowitz J. Minimally invasive posterior hamstring harvest. Arthroscopy Techniques. 2013; 2(3): e299e301, doi: 10.1016/j.eats.2013.04.008.

39. Yasin MN, Charalambous CP, Mills SP, et al. Accessory bands of the hamstring tendons: A clinical anatomical study. Clin Anat. 2010; 23(7): 862-865, doi: 10.1002/ ca. 21020 , indexed in Pubmed: 20607820.

40. Youen W. Female-to-male transsexual burgery - the state of the art. Hong Kong Med Assoc. 1996; 46(4): 268-73.

41. Zaffagnini S, Golanò P, Farinas $O$, et al. Vascularity and neuroreceptors of the pes anserinus: anatomic study. Clin Anat. 2003; 16(1): 19-24, doi: 10.1002/ca.10073, indexed in Pubmed: 12486734. 